Article

\title{
A Comparison of Ethylene-Tar-Derived Isotropic Pitches Prepared by Air Blowing and Nitrogen Distillation Methods and Their Carbon Fibers
}

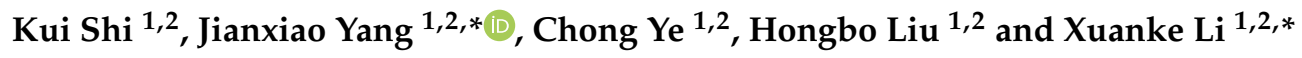 \\ 1 College of Materials Science and Engineering, Hunan University, Changsha 410082, Hunan, China; \\ skhnu123@163.com (K.S.); 15874950624@163.com (C.Y.); hndxlhb@163.com (H.L.) \\ 2 Hunan Province Key Laboratory for Advanced Carbon Materials and Applied Technology, Hunan \\ University, Changsha 410082, China \\ * Correspondence: yangjianxiao@hnu.edu.cn (J.Y.); xuankeli@hnu.edu.cn (X.L.); Tel.: +86-1521-100-5929 (J.Y.); \\ +86-1599-427-9703 (X.L.)
}

Received: 7 December 2018; Accepted: 15 January 2019; Published: 18 January 2019

\begin{abstract}
Two isotropic pitches were prepared by air blowing and nitrogen distillation methods using ethylene tar (ET) as a raw material. The corresponding carbon fibers were obtained through conventional melt spinning, stabilization, and carbonization. The structures and properties of the resultant pitches and fibers were characterized, and their differences were examined. The results showed that the introduction of oxygen by the air blowing method could quickly increase the yield and the softening point of the pitch. Moreover, the air-blown pitch (ABP) was composed of aromatic molecules with linear methylene chains, while the nitrogen-distilled pitch (NDP) mainly contained polycondensed aromatic rings. This is because the oxygen-containing functional groups in the ABP could impede ordered stack of pitch molecules and led to a methylene bridge structure instead of an aromatic condensed structure as in the NDP. Meanwhile, the spinnability of the ABP did not decrease even though it contained $2.31 \mathrm{wt} \%$ oxygen. In contrast, the ABP had narrower molecular weight distribution, which contributed to better stabilization properties and higher tensile strength of the carbon fiber. The tensile strength of carbon fibers from the ABP reached $860 \mathrm{MPa}$ with fiber diameter of about $10 \mu \mathrm{m}$, which was higher than the tensile strength of $640 \mathrm{MPa}$ for the NDP-derived carbon fibers.
\end{abstract}

Keywords: carbon fiber; ethylene tar; isotropic pitch; air blowing

\section{Introduction}

Carbon fibers ( $\mathrm{CFs}$ ) are widely used in the military, various industries, and sports because of their high mechanical properties, low density, and good conductive properties [1]. The raw materials of pitch-based CFs are usually coal or petroleum-derived by-products, which are abundant, low cost, and have high carbonization yield [2,3]. Therefore, more and more researchers are pursuing low-cost, pitch-based CFs because of their considerable advantage in price and extensive application prospects in the fields of automobiles, sporting goods, building materials, $\mathrm{C} / \mathrm{C}$ composites, activated carbon fibers, thermal field, etc. [4-9]. Based on this, a lot of raw materials and preparation methods of pitch precursor have been tried, including bromination and subsequent dehydrobromination of naphtha-cracked oil [3], tailored suitable molecular weight portion from Hyper-coal by methylnaphthalene [10], heat treatment of pyrolyzed fuel oil [11], and so on. Ethylene tar (ET) is the by-product of ethylene production, which is rich in resources, low cost, and has low ash content compared to other precursors, especially coal tar pitch, which usually contains primary quinoline insoluble that needs to be removed first. Accordingly, ET is expected to be an ideal raw material for preparing a spinnable pitch. In addition, 
atmospheric distillation and air blowing are the most common methods to prepare a spinnable pitch for CF production [12-16]. Compared to atmospheric distillation, which mainly involves the removal of light components and condensation polymerization of heavy components during the reaction, air blowing is recognized as an effective method to increase the softening point (SP) and the yield of the pitch. This is because oxidation can link molecules by methylene formed through oxidative dehydrogenation of aliphatic side chains or by oxygen-containing functional groups, such as $\mathrm{C}-\mathrm{O}-\mathrm{C}$ and $\mathrm{C}=\mathrm{O}$ bridge, formed through oxidation of aliphatic side chains $[12,15,17]$. Consequently, air blowing can also suppress the formation of mesophase to obtain a homogenous pitch [18]. There has been some research on air blowing of pitches, particularly focusing on the influence of different raw materials, such as coal tar pitch, petroleum pitch, and anthracene oil, or different conditions of air blowing on the final properties of air-blown pitches (ABP) [19-21]. However, these works only investigated the pitches and rarely referred to the preparation of CFs. As a matter of fact, when preparing CFs, oxygen is introduced not only during the air blowing process but also during the stabilization process in order to make the pitch fibers infusible and maintain the fiber shape during the carbonization process. The oxygen introduced in these two stages may have different behaviors during subsequent carbonization processes. Indeed, it is important to consider the oxygen that exists in the pitch precursor as it may lead to a different molecular structure, and the corresponding molecular structure of the pitch would then impact the spinnability of pitches as well as the stabilization and carbonization processes of pitch fibers. In this work, we propose that the oxygen introduced in the pitch precursor can improve the mechanical properties of the resultant CFs prepared at low carbonization temperature below $1200^{\circ} \mathrm{C}$ because the introduced oxygen in the pitch precursor is more stable than the introduced oxygen from the stabilization process.

Two kinds of ET-derived isotropic pitches were prepared by nitrogen distillation and air blowing methods in order to compare the differences in their molecular structures and clarify the influence of oxygen introduced during the preparation of the pitch precursor or during the stabilization process of pitch fibers on the properties of the corresponding CFs.

\section{Materials and Methods}

\subsection{Materials}

ET was supplied from Wuhan Luhua Yueda Chemical Co. Ltd (Wuhan, China). The ET was used as a raw material to prepare the spinnable pitches; ET is completely soluble in toluene.

\subsection{Preparation of Spinnable Pitches}

The air-blown pitch was prepared by the air blowing method as follows: (1) The ET was distilled at $250{ }^{\circ} \mathrm{C}$ in a $2 \mathrm{~L}$ stainless steel reactor to remove the light components to obtain a basic pitch. (2) The basic pitch was air blown at $280{ }^{\circ} \mathrm{C}$ for $3 \mathrm{~h}$ in $3 \mathrm{~L} / \mathrm{min}$ air atmosphere to attain oxidized pitch. (3) In order to get the spinnable pitch with high softening point (SP), the oxidized pitch was further heat-treated at $350{ }^{\circ} \mathrm{C}$ for $4 \mathrm{~h}$ in $3 \mathrm{~L} / \mathrm{min}$ nitrogen atmosphere. For comparison, the nitrogen-distilled pitch (NDP) with almost the same SP was prepared by heating the ET at $380{ }^{\circ} \mathrm{C}$ for $5 \mathrm{~h}$ in $3 \mathrm{~L} / \mathrm{min}$ nitrogen atmosphere.

\subsection{Preparation of Carbon Fibers}

The prepared NDP and ABP were spun into pitch fibers (PFs) at a temperature equal to their $\mathrm{SP}+80{ }^{\circ} \mathrm{C}$ using a melt-spinning method with a single-hole spinneret (diameter $=0.2 \mathrm{~mm}$, length/diameter $=3$ ). For this procedure, a laboratory spinning apparatus (Huizhong Dingcheng, Chengdu, China) was used with a nitrogen pressure of $0.4 \mathrm{MPa}$ and winding speeds of 300-500 rpm $(100 \mathrm{rpm}=60 \mathrm{~m} / \mathrm{min})$ to get PFs with different diameters. The spun PFs were stabilized by heating from room temperature to $280^{\circ} \mathrm{C}$ at a rate of $0.5^{\circ} \mathrm{C} / \mathrm{min}$ and then holding at this temperature for $1 \mathrm{~h}$ with an air flow of $500 \mathrm{~mL} / \mathrm{min}$. Then, the stabilized fibers (SFs) were successively carbonized at 
$1200{ }^{\circ} \mathrm{C}$ for $30 \mathrm{~min}$ at a heating rate of $5{ }^{\circ} \mathrm{C} / \mathrm{min}$ with a nitrogen flow rate of $100 \mathrm{~mL} / \mathrm{min}$. The resultant PFs, SFs, and CFs from the NDP and the ABP were labeled as NDP-PF, ABP-PF, NDP-SF, ABP-SF, NDP-CF, and ABP-CF, respectively.

\subsection{Characterization of Pitches and Carbon Fibers}

The SP of the pitch was determined by a CFT-100EX capillary rheometer (Shimadzu, Kyoto, Japan). The solubility of the pitch in $n$-hexane, toluene, and quinoline was determined using the Soxhlet extraction method (GB/T 26930.5-2011) to obtain $n$-hexane soluble (HS), $n$-hexane insoluble and toluene soluble (HI-TS), toluene insoluble and quinoline soluble (TI-QS), and quinoline insoluble (QI) fractions. Carbon, hydrogen, sulfur, and nitrogen contents were determined according to SN/T 4764-2017 with a Elementar Vario EL III elemental analyzer (Elementar, Langenselbold, Germany). The oxygen content was obtained by the subtraction method $(\mathrm{O}=100-\mathrm{C}-\mathrm{H}-\mathrm{N}-\mathrm{S})$. Fourier transform infrared (FT-IR) spectra were obtained using the $\mathrm{KBr}$ disc technique (sample $/ \mathrm{KBr}=1 / 100$ ) in a Nicolet iS10 FT-IR spectrometer (Thermo Fisher Scientific, Waltham, MA, USA). Each spectrum was an average of 32 scans with a resolution of $4 \mathrm{~cm}^{-1}$. The solution-state ${ }^{13} \mathrm{C}$ nuclear magnetic resonance $\left({ }^{13} \mathrm{C}-\mathrm{NMR}\right)$ spectra were obtained using a Bruker $600 \mathrm{MHz}$ Advance NMR spectrometer (Bruker, Karlsruhe, Germany). The quantitative ${ }^{13} \mathrm{C}$-NMR spectra were recorded by dissolving samples in $d$-chloroform $\left(\mathrm{CDCl}_{3}\right)$ solvent (sample $/ \mathrm{CDCl}_{3}=100 \mathrm{mg} / 1 \mathrm{~mL}$ ) with tetramethylsilane used as the chemical shift reference. The ${ }^{13} \mathrm{C}-\mathrm{NMR}$ spectra were quantitatively analyzed by the ratio of the peak integral area. X-ray diffraction (XRD) analyses were performed by a D8 Advance diffractometer (Bruker, Karlsruhe, Germany) with $\mathrm{Cu} \mathrm{K} \alpha$ radiation $(\lambda=0.15406 \mathrm{~nm})$ generated at $32 \mathrm{kV}$ and $50 \mathrm{~mA}$ with a scan speed of $1^{\circ} / \mathrm{min}$ for 2 theta values between $5^{\circ}$ and $80^{\circ}$. The thermogravimetric (TG) properties of samples were measured using a STA 449 F5 thermal analyzer (Netzsch, Selb, Germany). The thermal stability and coking value $(\mathrm{CV})$ of the obtained pitches were analyzed in $40 \mathrm{~mL} / \mathrm{min}$ nitrogen atmosphere with a heating rate of $5{ }^{\circ} \mathrm{C} / \mathrm{min}$ to $900{ }^{\circ} \mathrm{C}$. Meanwhile, to evaluate the stabilization properties of spun PFs, the obtained PFs were also analyzed by TG with different heating rates $\left(0.5^{\circ} \mathrm{C} / \mathrm{min}, 1^{\circ} \mathrm{C} / \mathrm{min}\right.$, $2{ }^{\circ} \mathrm{C} / \mathrm{min}, 4{ }^{\circ} \mathrm{C} / \mathrm{min}$ ) to $600{ }^{\circ} \mathrm{C}$ in $40 \mathrm{~mL} / \mathrm{min}$ air atmosphere to find their maximum weight gain $\left(\mathrm{W}_{\max }\right)$ and the corresponding maximum temperature $\left(\mathrm{T}_{\max }\right)$ as well as to calculate their reaction activation energy $\left(E_{a}\right)$. The gas released during the carbonization of PFs and SFs were measured by Hiden Analytical HAS-301-1474 mass spectrometer (Hiden Analytical, Warrington, UK) coupled with TG, which was heated from 20 to $1200^{\circ} \mathrm{C}$ at a rate of $10^{\circ} \mathrm{C} / \mathrm{min}$ and an argon flow of $20 \mathrm{~mL} / \mathrm{min}$. The MS was performed at RGA mode with a secondary electron multiplier, and the quartz capillary connected to the thermal analyzer was heated to $160^{\circ} \mathrm{C}$. The morphologies and the diameter of the CFs were observed by JSM-6700F field emission scanning electron microscope (SEM, JEOL, Tokyo, Japan) with $5 \mathrm{kV}$. The tensile strength and Young's modulus of CFs were measured at room temperature using monofilaments with a gauge length of $20 \mathrm{~mm}$ according to the standard (ASTM D4018-2011). The diameter of CFs was observed by SEM after the tensile experiment. The tensile strength and Young's modulus were evaluated from the mean value of 30 tests, with the values distributing within $10 \%$.

\section{Results and Discussion}

\subsection{Characterization of NDP and $A B P$}

The general characteristics of pitches are summarized in Table 1. The yield of the ABP was higher than that of the NDP, and their SP was almost the same. This result is in line with results from previous researches because the air blowing method can increase SP more quickly [17]. It was apparent that air blowing brought large amounts of oxygen into the pitch as the oxygen content of the ABP was up to $2.31 \%$. This was higher than the oxygen content of the NDP, which was $0.78 \%$. Compared to the ET, the solubility of the NDP and the ABP in $n$-hexane and toluene decreased; HI-TS increased from $48.4 \%$ for the ET to $59.8 \%$ and $83.2 \%$ for the NDP and the ABP, respectively, as shown 
in Figure 1. It should be noted that TI appeared in both the NDP and the ABP, but the TI of the NDP was larger than that of the ABP. In addition, QI appeared in the NDP, which demonstrated that the nitrogen distillation method was more effective in accelerating the polymerization reaction and forming larger molecules than the air blowing method [22]. This could also be confirmed by the larger $\mathrm{C} / \mathrm{H}$ atom rate of the NDP compared to the ABP, i.e., 1.40 and 1.26, respectively. Although the NDP had larger molecules, it is believed that the molecular weight distribution of the ABP was narrower and more uniform than the NDP due to its quite high HI-TS content. The SP of ABP was equal to that of the NDP, even at lower treatment temperature, because larger molecules were produced through oxidative cross-linking of small molecules when air blowing. Meanwhile, oxidative cross-linking suppressed molecule aggregation and uneven polymerization that might happen in the nitrogen distillation process. This more homogeneous composition of ABP would be beneficial for its spinning performance.

Table 1. Softening point (SP), pitch yield, and elemental analysis results of the air-blown pitch (ABP) and the nitrogen-distilled pitch (NDP).

\begin{tabular}{ccccccccc}
\hline \multirow{2}{*}{ Sample } & \multirow{2}{*}{ SP $\left({ }^{\circ} \mathbf{C}\right)$} & \multirow{2}{*}{ Yield (\%) } & \multicolumn{7}{c}{ Elemental Analysis (\%) } \\
\cline { 4 - 9 } & & & $\mathbf{C}$ & $\mathbf{H}$ & $\mathbf{N}$ & $\mathbf{S}$ & $\mathbf{O}$ & $\mathbf{C} / \mathbf{H}$ \\
\hline NDP & 253 & 22 & 93.53 & 5.56 & 0.02 & 0.04 & 0.78 & 1.40 \\
ABP & 252 & 28 & 91.55 & 6.06 & 0.05 & 0.10 & 2.31 & 1.26 \\
\hline
\end{tabular}

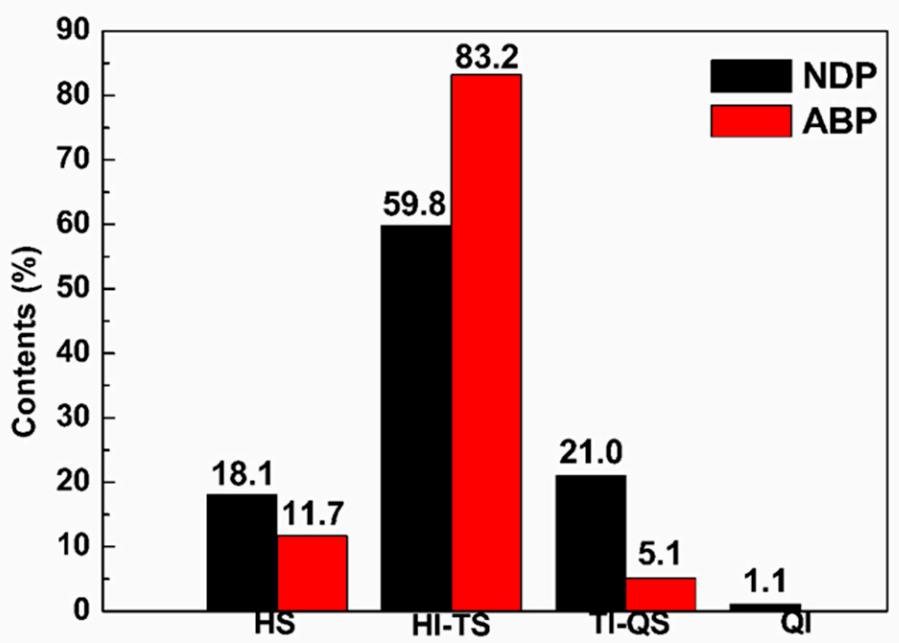

Figure 1. Solubility parameter (n-hexane soluble (HS), n-hexane insoluble and toluene soluble (HI-TS), toluene insoluble and quinoline soluble (TI-QS), and quinoline insoluble (QI)) of the NDP and the ABP.

FT-IR analyses, shown in Figure 2, were carried out to verify the functional groups in the NDP and the ABP. The absorption peaks at $3050 \mathrm{~cm}^{-1}$ and $1600 \mathrm{~cm}^{-1}$ were assigned to the presence of aromatic C-H and aromatic C-C stretching vibrations, respectively. The stronger absorbance at $2920 \mathrm{~cm}^{-1}$ and $2850 \mathrm{~cm}^{-1}$ in the ABP corresponded to methylene hydrogen asymmetric and symmetric stretching vibrations, respectively [23]. The peak at $1450 \mathrm{~cm}^{-1}$ corresponding to methylene hydrogen bending vibration was clearly strong in intensity. The broad peak at $3300-3600 \mathrm{~cm}^{-1}$ might be ascribed to hydroxyl of $\mathrm{H}_{2} \mathrm{O}$ in the pitches [24]. It must also be mentioned that a new peak appeared at $1700 \mathrm{~cm}^{-1}$ for the ABP compared to the NDP, which was assigned to the $\mathrm{C}=\mathrm{O}$ stretching vibration. This could be easily explained by the higher oxygen content of the ABP, as shown in Table 1. Another weak bond at $1260 \mathrm{~cm}^{-1}$ belonging to the $\mathrm{C}-\mathrm{O}$ stretching vibration could also be observed. The emergence of oxygen-containing functional groups indicated that oxygen might connect pitch molecules as an oxygen bridge by air blowing. 


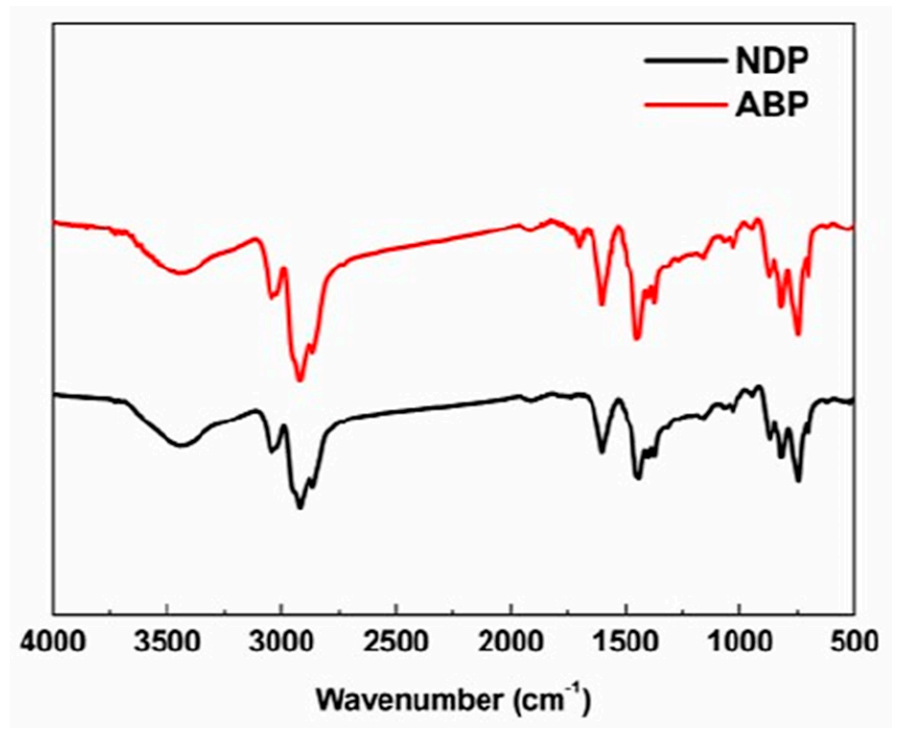

Figure 2. FT-IR spectra of the NDP and the ABP.

In order to further study the molecular structure of the NDP and the $\mathrm{ABP},{ }^{13} \mathrm{C}-\mathrm{NMR}$ was performed. The ${ }^{13} \mathrm{C}-\mathrm{NMR}$ spectra of the NDP and the ABP are plotted in Figure 3. The normalized integration data of ${ }^{13} \mathrm{C}-\mathrm{NMR}$ spectra is presented in Table 2. The larger aromaticity of the NDP could be demonstrated by larger $C_{a r} / C_{a l}$ compared to the ABP, i.e., 5.29 and 2.85, respectively. Most of the aromatic carbon in NDP was $\mathrm{C}_{\text {ar1,3, }}$, suggesting abundant pericondensed structure in the NDP [25]. This result indicated more condensed large molecules in the NDP produced by heat treatment, which was reflected by the higher insoluble content, as shown in Figure 1. More aliphatic carbon in the form of $\mathrm{CH}_{2}$ and $\mathrm{C}_{\alpha 2}$ in the ABP compared to the NDP indicated more methylene bridge structures in the $\mathrm{ABP}$, formed by oxidative dehydrogenation, which is in accordance with the above analysis.

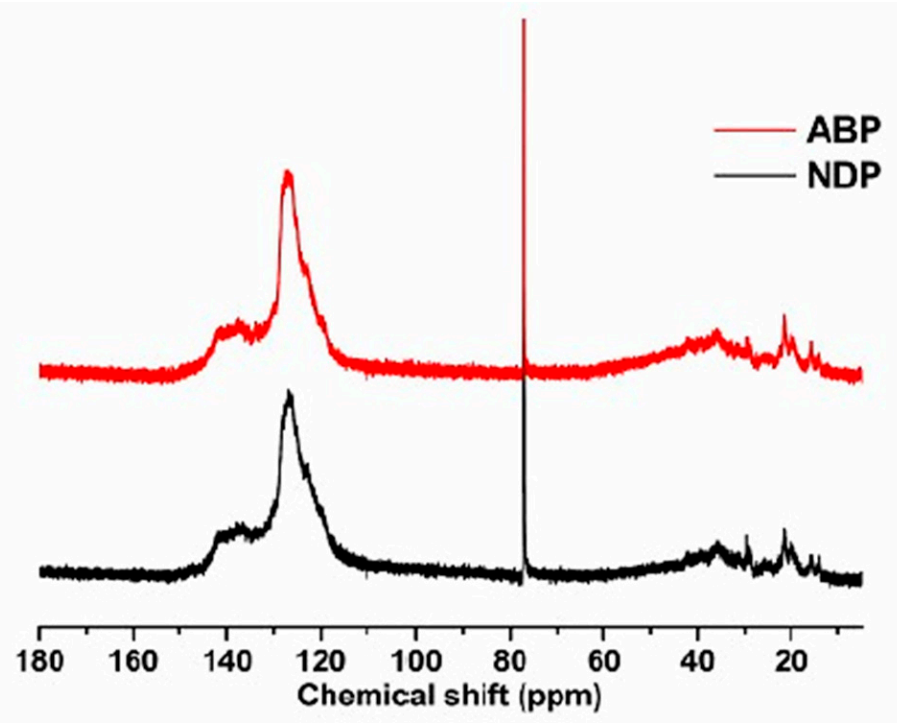

Figure $3 .{ }^{13} \mathrm{C}-\mathrm{NMR}$ spectra of the NDP and the ABP. 
Table 2. Normalized integration data based on the ${ }^{13} \mathrm{C}$ NMR spectra.

\begin{tabular}{|c|c|c|c|c|c|c|c|c|}
\hline \multirow{2}{*}{ Samples } & \multicolumn{3}{|c|}{$\mathrm{C}_{\mathrm{al}}$} & \multicolumn{2}{|c|}{$\mathrm{C}_{\mathrm{ar}}$} & \multirow{2}{*}{$\mathrm{C}_{\mathrm{al}}$} & \multirow{2}{*}{$\mathrm{C}_{\mathrm{ar}}$} & \multirow{2}{*}{$\mathrm{C}_{\mathrm{ar}} / \mathrm{C}_{\mathrm{al}}$} \\
\hline & $\mathrm{CH}_{3}$ & $\mathrm{CH}_{2}$ & $\mathrm{C}_{\alpha 2}$ & $\mathrm{C}_{\mathrm{ar} 1,3}$ & $\mathrm{C}_{\mathrm{ar} 1,2}$ & & & \\
\hline NDP & 0.04 & 0.08 & 0.04 & 0.60 & 0.24 & 0.16 & 0.84 & 5.29 \\
\hline $\mathrm{ABP}$ & 0.03 & 0.14 & 0.09 & 0.52 & 0.22 & 0.26 & 0.74 & 2.85 \\
\hline
\end{tabular}

$\mathrm{CH}_{3}$, methyl carbon; $\mathrm{CH}_{2}$, methylene $\left(\mathrm{CH}_{2}\right)$ carbon $\alpha$ or further from an aromatic ring in free side chain; $\mathrm{C}_{\alpha 2}$, $\mathrm{CH}_{2}$ carbon in bridge/hydroaromatic structures; $\mathrm{Car}_{1,3}$, pericondensed aromatic carbon $\left(\mathrm{C}_{\mathrm{ar} 3}\right)$ and protonated aromatic carbon $\left(\mathrm{CH}_{\mathrm{ar}}\right) ; \mathrm{Car}_{1,2}$, catacondensed aromatic carbon, aromatic carbon with both heteroatomic or aromatic substituents $\left(\mathrm{C}_{\mathrm{ar} 2}\right)$, and the region correspondent to aromatic carbon joined to aliphatic chains; $\mathrm{C}_{\mathrm{al}}$, total aliphatic carbon; $\mathrm{C}_{\mathrm{ar}}$, total aromatic carbon.

Figure 4 shows the XRD graphs of the NDP and the ABP. Both of them showed broad peaks between $10^{\circ}$ and $30^{\circ}$. Peaks between $10^{\circ}$ and $20^{\circ}$ were attributable to asphaltene components, while those between $20^{\circ}$ and $30^{\circ}$ were attributable to stacked molecular structures [26]. Therefore, the stacked structure was more evident in the NDP than that in the ABP due to larger condensed aromatic molecules in the NDP, as shown in Figure 1. In contrast, the oxygen in the ABP impeded ordered stack of molecules. Nevertheless, more symmetrical peak of ABP may indicate more uniform composition, which is consistent with the extraordinarily uniform components presented in Figure 1.

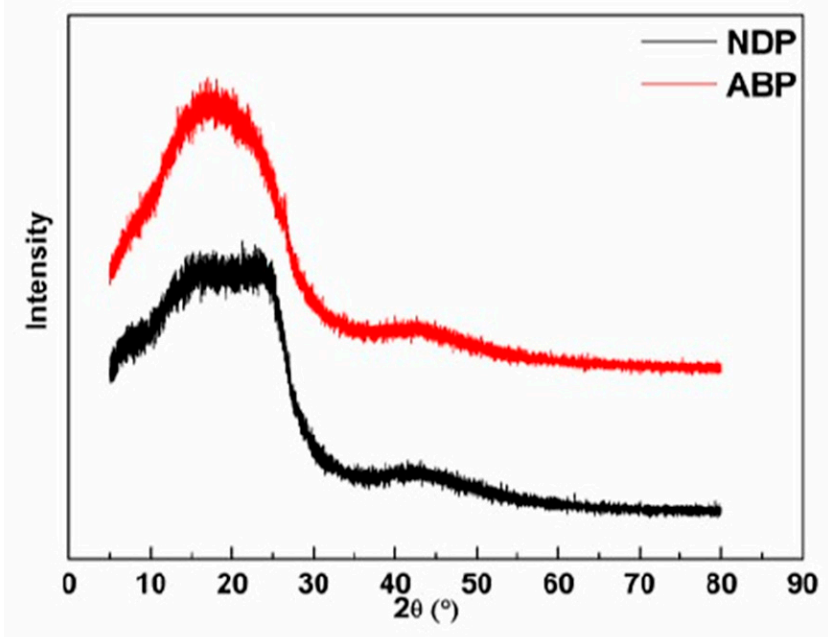

Figure 4. X-ray diffractograms of the NDP and the ABP.

\subsection{Spinning Properties of NDP and $A B P$}

The viscosity-temperature curves of NDP and ABP are shown in Figure 5. The viscosity of both the NDP and the ABP decreased sharply with increasing temperature when the temperature was lower than $310^{\circ} \mathrm{C}$, then decreased gradually to about $330^{\circ} \mathrm{C}$, while the viscosity-temperature curves became almost flat above $330^{\circ} \mathrm{C}$ because of the temperature sensitive property of the pitch. It can be seen that the viscosity-temperature curve of the ABP showed two jumping steps between $310{ }^{\circ} \mathrm{C}$ and $330^{\circ} \mathrm{C}$, which suggested that the ABP had worse spinning performance than the NDP. However, both of them had excellent spinning performance when the NDP and the ABP were spun into PFs by the melt-spinning method at $335^{\circ} \mathrm{C}$. Therefore, the results indicated that the spinnability of the ABP had not deteriorated even though it had more oxygen, which is usually considered as an impurity atom. This may be attributed to the homogenous components of the $\mathrm{ABP}$, as previously mentioned. 


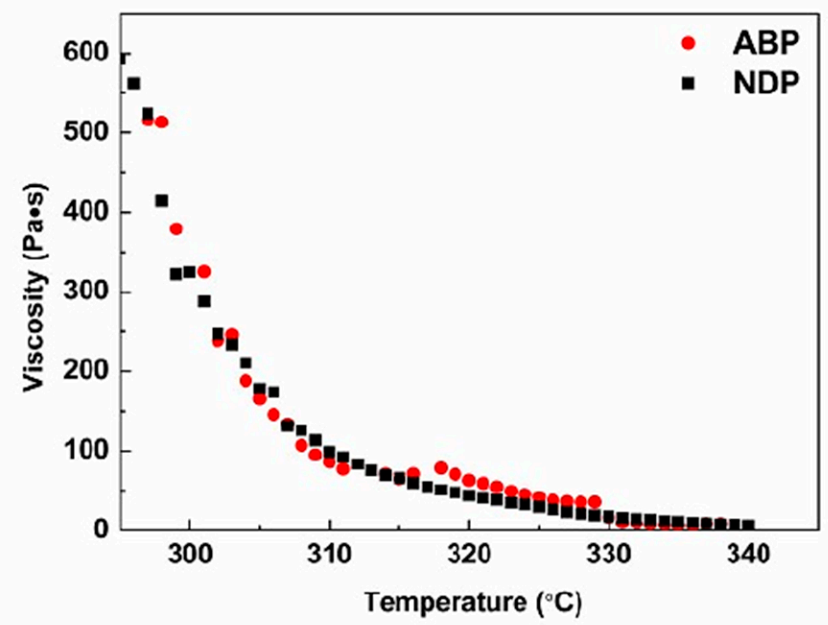

Figure 5. Viscosity-temperature curves of the NDP and the ABP.

\subsection{Stabilization and Carbonization of NDP-PF and ABP-PF}

Stabilization is a crucial process to determine the properties of CFs due to the formation of intermolecular cross-linking in an oxidizing atmosphere, which can ensure that the shape of fibers do not change in subsequent carbonization processes [27]. Therefore, proper stabilization parameter should be adopted. In order to optimize the stabilization process, TG was used to measure the oxidation reactivity of PFs, and the results are presented in Figure 6. The lower initial temperature of weight gain indicated higher oxidation reactivity of ABP-PF compared to NDP-PF. This was also proven by the lower $\mathrm{E}_{\mathrm{a}}$ and $\mathrm{T}_{\max }$ of $\mathrm{ABP}-\mathrm{PF}$, as shown in Table 3. The higher oxidation reactivity of ABP-PF might have been due to the lightest components remaining in the ABP instead of being removed by distillation at high temperature as in the NDP. However, the $\mathrm{W}_{\max }$ in oxidation of ABP-PF was less than NDP-PF, i.e., $11.6 \%$ and $12.8 \%$, respectively, as exhibited in Table 3 . This result could be interpreted as showing that the higher oxygen in the ABP could restrain more oxygen from diffusing into the PFs. This viewpoint can be demonstrated by the similar oxygen content of NDP-SF and ABP-SF, as presented in Table 3.

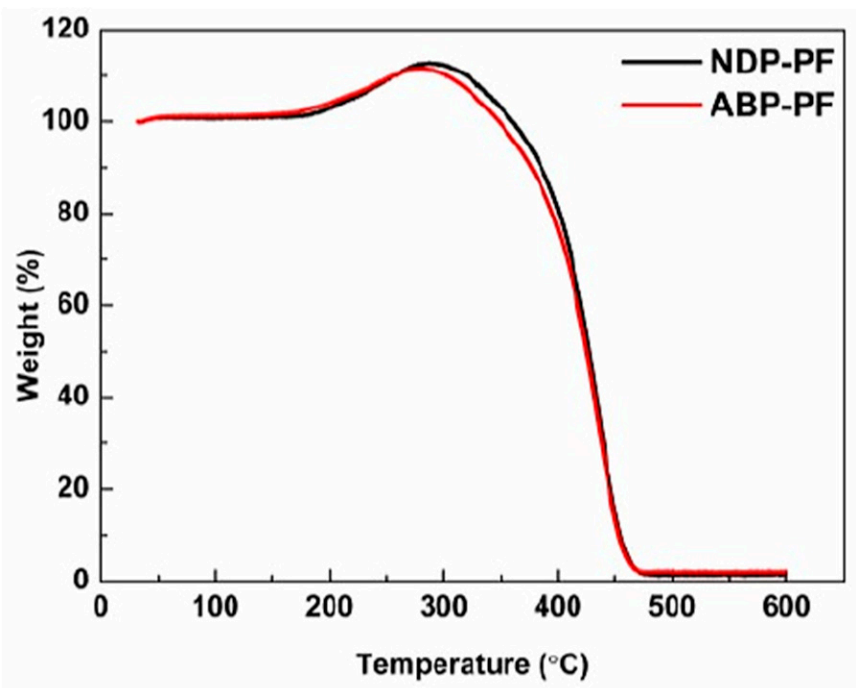

Figure 6. Thermogravimetric (TG) curves of NDP-PF and ABP-PF during stabilization process in air atmosphere. 
Table 3. Oxidation and carbonization properties of pitch fibers.

\begin{tabular}{cccccc}
\hline Samples & $\mathbf{T}_{\max }\left({ }^{\circ} \mathbf{C}\right)$ & $\mathbf{W}_{\max }(\mathbf{\%})$ & $\mathbf{E}_{\mathbf{a}}(\mathbf{k J} / \mathbf{m o l})$ & Oxygen Content $(\%)$ & Yield (\%) \\
\hline NDP-SF & 286 & 12.8 & 124.5 & 25.46 & 114.0 \\
ABP-SF & 278 & 11.6 & 120.5 & 25.72 & 112.5 \\
NDP-CF & - & - & - & 8.96 & 71.3 \\
ABP-CF & - & - & - & 10.29 & 71.0 \\
\hline
\end{tabular}

$\mathrm{T}_{\max }, \mathrm{W}_{\max }$, and $\mathrm{E}_{\mathrm{a}}$ were calculated from TG results of NDP-PF and ABP-PF in air atmosphere.

After $1200{ }^{\circ} \mathrm{C}$ carbonization, both NDP-CF and ABP-CF had high yield over $70 \%$, which is favorable for producing low-cost, general-purpose CFs. Higher oxygen content of ABP-CF compared to NDP-CF, as shown in Table 3, denoted that less oxygen of ABP-CF was given off during the carbonization process in view of the similar oxygen content of NDP-SF and ABP-SF. Less gas was released in the carbonization process of ABP-SF (35.7\%) compared to the NDP-SF (37.7\%), which might be beneficial for the mechanical properties of CFs because fewer defects would be generated. This also illustrates that the oxygen existing in the pitch precursor was more stable than that introduced in the stabilization process. This could be verified by the TG-MS results of the $\mathrm{CO}$ and $\mathrm{CO}_{2}$ given off from oxygen-containing groups of fibers during carbonization process for NDP-SF and ABP-PF, as shown in Figure $7 \mathrm{a}, \mathrm{b}$. Both $\mathrm{CO}$ and $\mathrm{CO}_{2}$ were released at two stages; the first peak was located at $400-800{ }^{\circ} \mathrm{C}$ and $270-850{ }^{\circ} \mathrm{C}$, respectively. Then, the amount of release began to increase rapidly for both $\mathrm{CO}$ and $\mathrm{CO}_{2}$, especially for NDP-SF. It should be noted that the difference in the release amount of $\mathrm{CO}_{2}$ for NDP-SF and ABP-PF was more distinct. The NDP-SF revealed higher peak intensity and magnitude of $\mathrm{CO}_{2}$ in both stages, especially the high temperature stage, compared to ABP-PF. This showed that the removal of oxygen was more arduous below $1200^{\circ} \mathrm{C}$ when the oxygen was from the pitch precursor introduced by air blowing than the oxygen from the stabilization process. Therefore, moderate amounts of oxygen in the pitch precursor could improve the stabilization and carbonization properties of PFs.
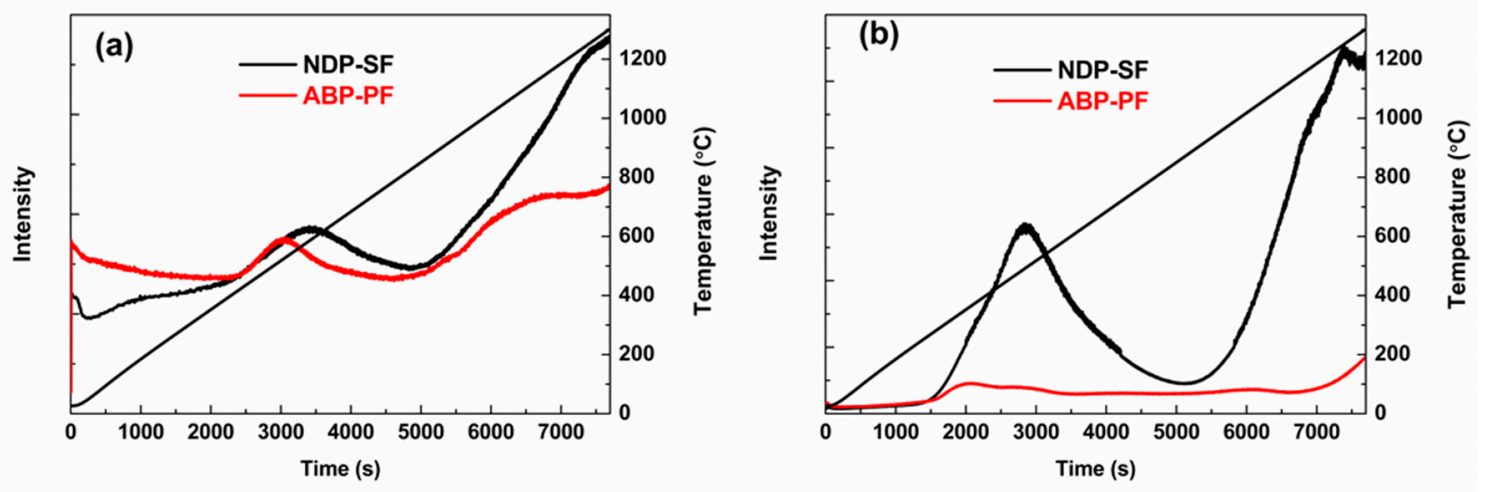

Figure 7. MS curves of NDP-SF and ABP-PF during carbonization process in argon (a) $\mathrm{CO}$ and (b) $\mathrm{CO}_{2}$.

\subsection{Morphology and Mechanical Properties of NDP-CF and ABP-CF}

The SEM micrographs of CFs are shown in Figure 8. ABP-CF expressed more homogeneous and smooth surfaces and cross sections compared to NDP-CF, corresponding to more homogeneous precursor pitch. Moreover, the CFs exhibited no fusing, indicating that the stabilization process had been adequate. The cross section of the CFs showed a glass-like fracture surface, indicating that the precursor pitch was isotropic. The tensile strength and Young's modulus of CFs are presented in Figure 9. ABP-CF had a tensile strength of 550-895 MPa and modulus of 31-45 GPa when the diameter decreased from 14.1 to $9.8 \mu \mathrm{m}$; these figures were consistently higher than for NDP-CF, which had tensile strength of 448-748 MPa and modulus of 27-35 GPa as the diameter decreased from 13.1 to $8.7 \mu \mathrm{m}$. In both cases, the tensile strength decreased with increasing diameter. The mechanical properties reached the level of commercial, general-purpose CFs. Higher tensile strength can be attributed to the uniform composition of the $\mathrm{ABP}$ and less gas released in the carbonization process, 
which can produce defects in CFs due to the existence of oxygen, as previously discussed. Whether the greater amount of oxygen, which would be removed at higher temperature above $1200^{\circ} \mathrm{C}$ had an unfavorable effect on the properties of CFs needs further investigation.
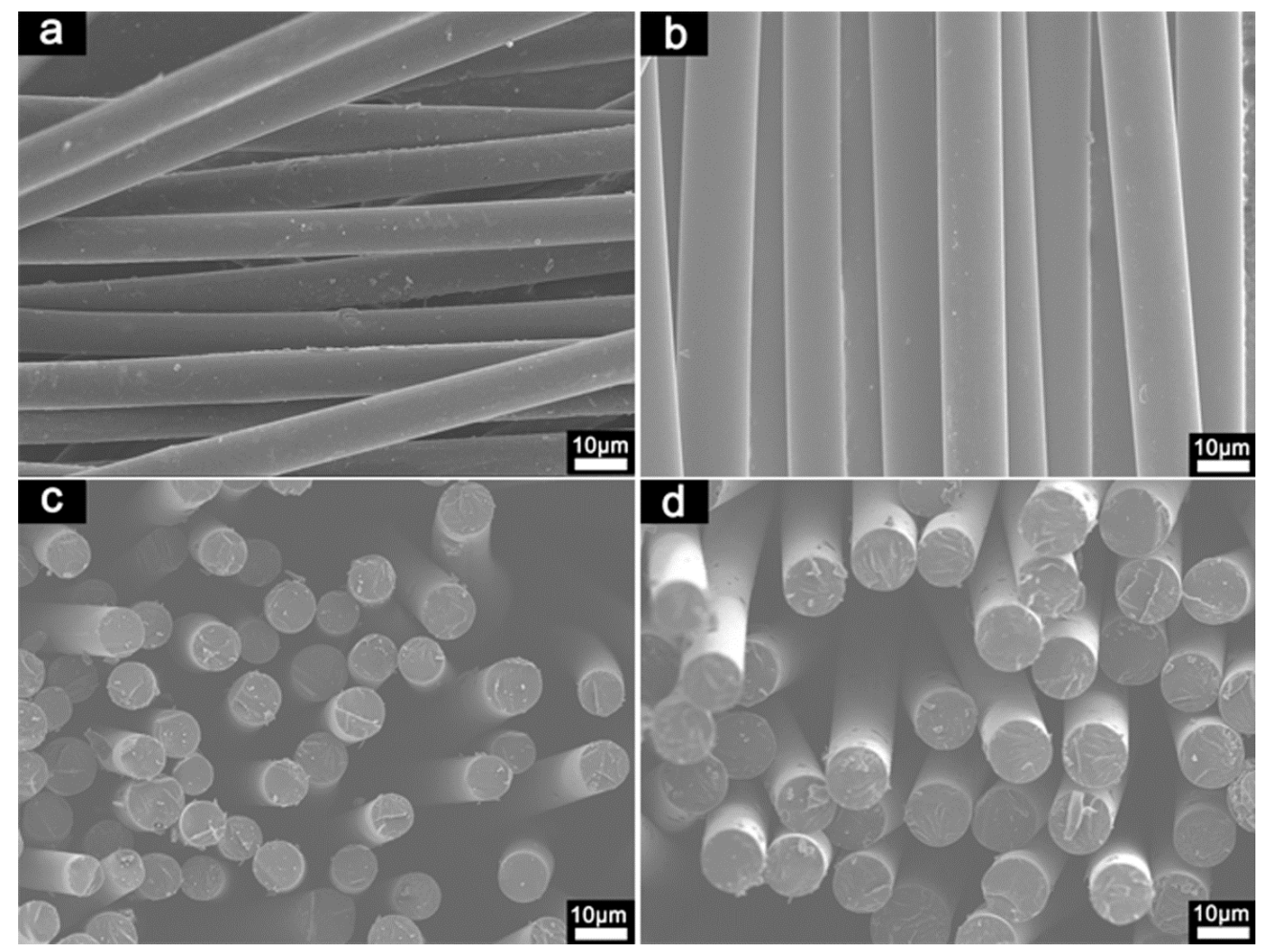

Figure 8. SEM micrographs of $(\mathbf{a}, \mathbf{c})$ NDP-CF and $(\mathbf{b}, \mathbf{d})$ ABP-CF.

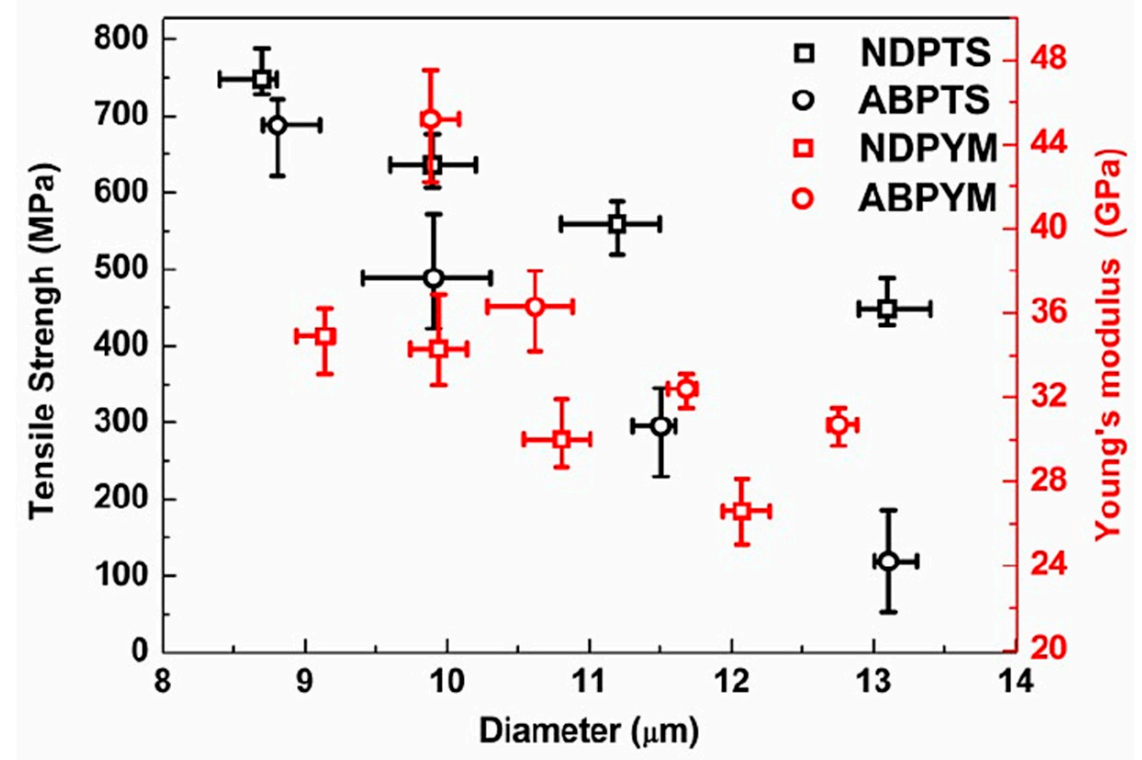

Figure 9. The mechanical properties of NDP-CF and ABP-CF.

\section{Conclusions}

Two isotropic pitches were prepared through atmospheric distillation and air blowing, respectively. The ABP had a higher yield and more homogeneous composition than the NDP because oxygen could connect smaller molecules and suppress the ordered stack of larger molecules. The oxygen existing in the pitch precursor was harder to remove during carbonization, contributing to higher tensile strength 
of ABP-CF compared to NDP-CF. The tensile strengths of ABF-CF and NDP-CF were $860 \mathrm{MPa}$ and $640 \mathrm{MPa}$, respectively, when the diameter was about $10 \mu \mathrm{m}$, and the modulus was $41 \mathrm{GPa}$ and $33 \mathrm{GPa}$, respectively. The results revealed that the oxygen introduced during the pitch precursor preparation process made a significant difference compared to the PF stabilization process. The evolution of introduced oxygen during the pitch precursor, stabilization, and carbonization processes will be investigated in detail in future work.

Author Contributions: Conceptualization, J.Y. and X.L.; Methodology, K.S.; Validation, K.S., J.Y., C.Y., H.L., and K.S.; Formal analysis, K.S. and J.Y.; Investigation, K.S.; Data curation, K.S. J.Y., and X.L.; Writing-original draft preparation, K.S.; Writing—review and editing, J.Y. and X.L.; Supervision, H.L.; Project administration, X.L.; Funding acquisition, J.Y. and X.L.

Funding: This research was funded by (i) the Key Project of Chinese National Programs (2016YFB0101702), (ii) the National Science Foundation for Young Scientists of China (Grant No. 51702094), and (iii) the Natural Science Foundation for Young Scientists of Hunan Province, China (Grant No. 2017JJ3014).

Acknowledgments: The authors appreciate the support of Wuhan Luhua Yueda Chemical Co. Ltd, China, for providing the ET.

Conflicts of Interest: The authors declare no conflict of interest.

\section{References}

1. Frank, E.; Steudle, L.M.; Ingildeev, D. Carbon Fibers: Precursor Systems, Processing, Structure, and Properties. Angew. Chem. Int. Ed. 2014, 53, 5262-5298. [CrossRef] [PubMed]

2. Mochida, I.; Toshima, H.; Korai, Y. Blending mesophase pitch to improve its properties as a precursor for carbon fibre I. Blending of PVC pitch into coal tar and petroleum-derived mesophase pitches. J. Mater. Sci. 1988, 23, 670-677. [CrossRef]

3. Kim, B.; Eom, Y.; Kato, O. Preparation of carbon fibers with excellent mechanical properties from isotropic pitches. Carbon 2014, 77, 747-755. [CrossRef]

4. Mora, E.; Blanco, C.; Prada, V. A study of pitch-based precursors for general purpose carbon fibers. Carbon 2002, 40, 2719-2725. [CrossRef]

5. Xu, Y.; Chung, D.D.L. Silane-treated carbon fiber for reinforcing cement. Carbon 2001, 39, $1995-2001$. [CrossRef]

6. Fu, X.; Lu, W.; Chung, D.D.L. Ozone treatment of carbon fiber for reinforcing cement. Carbon 1998, 36, 1337-1345. [CrossRef]

7. Chand, S. Review carbon fibers for composites. J. Mater. Sci. 2000, 35, 1303-1313. [CrossRef]

8. Shirvanimoghaddam, K.; Hamim, S.U.; Karbalaei, A.M. Carbon fiber reinforced metal matrix composites: Fabrication processes and properties. Compos. Part A-Appl. Sci. 2017, 92, 70-96. [CrossRef]

9. Park, S.H.; Kim, C.; Choi, Y.O. Preparations of pitch-based CF/ACF webs by electrospinning. Carbon 2013, 41, 2655-2657. [CrossRef]

10. Yang, J.; Nakabayashi, K.; Miyawaki, J. Preparation of pitch based carbon fibers using Hyper-coal as a raw material. Carbon 2016, 106, 28-36. [CrossRef]

11. Kim, J.G.; Kim, J.H.; Song, B. Synthesis and its characterization of pitch from pyrolyzed fuel oil (PFO). J. Ind. Eng. Chem. 2016, 36, 293-297. [CrossRef]

12. Barr, J.B.; Lewis, I.C. Chemical changes during the mild air oxidation of pitch. Carbon 1978, 16, $439-444$. [CrossRef]

13. Mochida, I.; Inaba, T.; Korai, Y. Carbonization properties of carbonaceous substances oxidized by air blowing-I: Carbonization behaviors and chemical structure of residual oils oxidized by air blowing. Carbon 1983, 21, 543-552. [CrossRef]

14. Mochida, I.; Inaba, T.; Korai, Y. Carbonization properties of carbonaceous substances oxidized by air blowing-II: Acid-catalyzed modification of oxidized residual oil for better anisotropic development. Carbon 1983, 21, 553-558. [CrossRef]

15. Blanco, C.; Santamar, A.R.; Bermejo, J. A comparative study of air-blown and thermally treated coal-tar pitches. Carbon 2000, 38, 517-523. [CrossRef]

16. Menendez, R.; Blanco, C.; Santamaria, R. On the chemical composition of thermally treated coal-tar pitches. Energy Fuels 2001, 15, 214-223. [CrossRef] 
17. Prada, V.; Granda, M.; Bermejo, J. Preparation of novel pitches by tar air-blowing. Carbon 1999, 37, 97-106. [CrossRef]

18. Maeda, T.; Zeng, S.M.; Tokumitsu, K. Preparation of isotropic pitch precursors for general purpose carbon fibers (GPCF) by air blowing-I. Preparation of spinnable isotropic pitch precursor from coal tar by air blowing. Carbon 1993, 31, 407-412. [CrossRef]

19. Zeng, S.M.; Maeda, T.; Tokumitsu, K. Preparation of isotropic pitch precursors for general purpose carbon fibers (GPCF) by air blowing-II. Air blowing of coal tar, hydrogenated coal tar, and petroleum pitches. Carbon 1993, 31, 413-419. [CrossRef]

20. Fernández, J.J.; Figueiras, A.; Granda, M. Modification of coal-tar pitch by air-blowing-I. Variation of pitch composition and properties. Carbon 1995, 33, 295-307. [CrossRef]

21. Fernández, A.L.; Granda, M.; Bermejo, J. Air-blowing of anthracene oil for carbon precursors. Carbon 2000, 38, 1315-1322. [CrossRef]

22. Mishra, A.; Saha, M.; Bhatia, G. A comparative study on the development of pitch precursor for general-purpose carbon fibres. J. Mater. Process. Tech. 2005, 168, 316-320. [CrossRef]

23. Wu, B.; Hu, H.; Zhao, Y. XPS analysis and combustibility of residues from two coals extraction with sub- and supercritical water. J. Fuel. Chem. Technol. 2009, 37, 385-392. [CrossRef]

24. Matsumoto, T.; Mochida, I. A structural study on oxidative stabilization of mesophase pitch fibers derived from coal tar. Carbon 1992, 30, 1041-1046. [CrossRef]

25. Andersen, S.I.; Jensen, J.O.; Speight, J.G. X-ray Diffraction of subfractions of petroleum asphaltenes. Energy Fuels 2005, 19, 2371-2377. [CrossRef]

26. Korai, Y.; Mochida, I. Molecular assembly of mesophase and isotropic pitches at their fused states. Carbon 1992, 30, 1019-1024. [CrossRef]

27. Drbohlav, J.; Stevenson, W.T.K. The oxidative stabilization and carbonization of a synthetic mesophase pitch, part I: The oxidative stabilization process. Carbon 1995, 33, 693-711. [CrossRef]

(C) 2019 by the authors. Licensee MDPI, Basel, Switzerland. This article is an open access article distributed under the terms and conditions of the Creative Commons Attribution (CC BY) license (http:// creativecommons.org/licenses/by/4.0/). 